\title{
A itinerância da vida manoki
}

\author{
ANDRÉ LoPES \\ Universidade de Sáo Paulo, São Paulo, Sáo Paulo, Brasil
}

DOI: $10.11606 /$ issn.2316-9133v22i22p137-143

Durante a vida das pessoas manoki diversas fases se sucedem e, com elas, certos afazeres tornam-se mais ou menos corriqueiros, cotidianos ou mesmo imprescindíveis. No entanto, observa-se uma itinerância permanente na maior parte dessas atividades, em pessoas de todas as idades. O modo manoki de vivenciar o cotidiano é muito marcado por um caráter periódico e sazonal, já que inúmeras atividades são abandonadas, mas voltam a ser realizadas em contextos distintos. Apesar de enfatizar aqui a produção indígena numa acepção mais econômica, é importante compreendê-la em um sentido amplo: como atividade que faça parte da fabricação de objetos, alimentos, pessoas, eventos ou relaçóes. Podemos notar diversos exemplos dessa itinerância produtiva durante a vida de uma pessoa manoki.

Após um período de intensa proximidade com suas mães, as crianças perambulam em pe- quenos grupos à procura de novas distraçóes. A "gurizada" está na maior parte do dia pelo terreiro das aldeias e dificilmente se entretém com uma só atividade durante muito tempo. Sujam-se e banham-se diversas vezes ao multiplicarem suas brincadeiras entre terra e água. Ao passar do tempo, os meninos já crescidos passam por iniciaçóes à vida adulta, das quais as mais relevantes são a introdução à casa dos homens na aldeia e as primeiras idas ao trabalho nas fazendas da região. Além da vida sazonal de "peão", a venda de pequi na estrada também fornece uma pequena renda para acessar mercadorias da cidade. A dedicação aos estudos e ao futebol ganha espaço no cotidiano, que passa a ser marcado também pela internet, festas e visitas a outras aldeias e cidades, abrindo caminhos para os primeiros romances.

Depois que se unem, os "casados novos" passam a se preocupar principalmente com a produção e compra de alimentos para a família que se forma. A intermitência entre ciclos 
I38 | ANDRÉ LOPES

de atividades produtivas, que costumam durar uma temporada de alguns meses, se faz presente na vida dessas pessoas: dificilmente alguém se dedica a uma só atividade durante um longo período de tempo. "Enjoadas" da repetição de certos afazeres cotidianos, elas deixam de se dedicar temporariamente às mais variadas tarefas, tais como roças, hortas, criaçôes de abelhas, galinhas, porcos ou gado, construção de casas, ou prestação de serviços para a comunidade (como a participação em conselhos e na associação, ou mesmo a própria chefia, que também não tende à permanência). A cobiçada opção dos empregos públicos dentro das comunidades gera um novo problema: mesmo "enjoadas" das tarefas rotineiras, as pessoas continuam presas às mesmas por conta da responsabilidade que assumem e da dependência da renda mensal. A aposentadoria que chega com os anos traz também a possibilidade de múltiplos afazeres cotidianos. De acordo com as sazonalidades específicas e suas vontades pessoais, os "velhos" podem se dedicar a um sem número de atividades, geralmente voltadas às práticas agrícolas e de confecção de objetos.

Essa itinerância produtiva manoki também se relaciona a uma adesão social mais ampla às atividades: dificilmente alguém se dedica de forma solitária a algum afazer, mas em geral se “anima” em razão de outras pessoas ou famílias estarem realizando a mesma ação. Além disso, apesar do abandono temporário de alguma atividade, a possibilidade de se dedicar novamente à mesma ocupação renunciada sempre permanece em aberto. Ao contrário de uma ideia de especialização ou estabilidade profissional, a itinerância parece trazer consigo um ideal de pessoa caracterizado por uma certa "erudição produtiva”, um saber-fazer muitas coisas necessárias durante a vida, e que poderia ser traduzido pela expressão "taka'a" (aquele que sabe). O conhecimento dessas diversas técnicas permite não só a itinerância de atividades, mas também a circulação em diversos espaços sociais, ambas formas que tendem a uma maior fluidez e inconstância. É preciso idealmente saber plantar, vender, dirigir, construir, escrever, filmar, gerir recursos em "projetos" e assim por diante...

autor

\section{André Lopes}

Mestrando em Antropologia Social / PPGAS-USP

Recebido em 29/05/2013

Aceito para publicação em 30/10/2013 


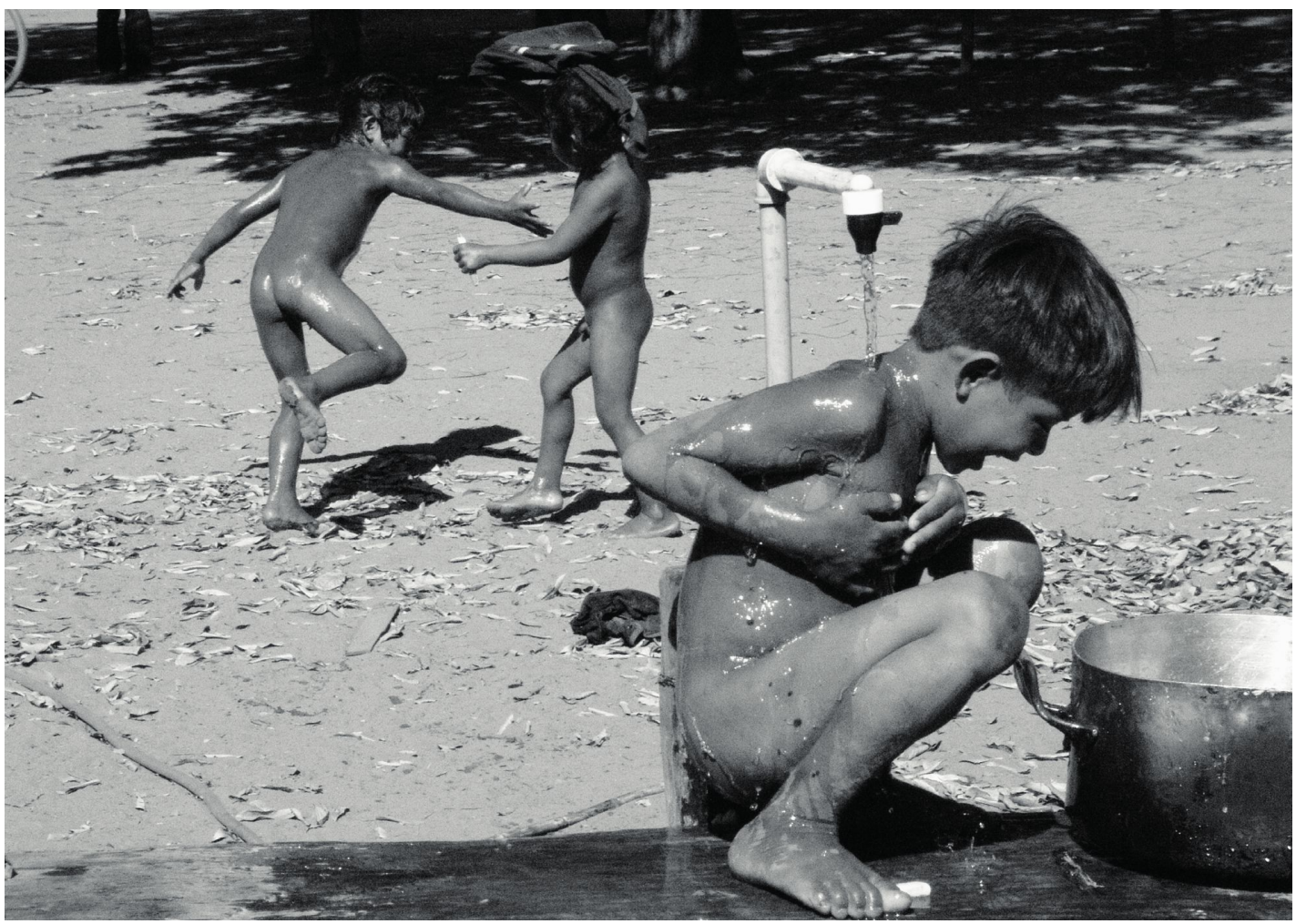

1. "Gurizada" da aldeia 13 de maio: na luta de roupas entre primos, o banho de torneira faz parte da diversão (sujou-limpou, limpou-sujou). Autor: André Lopes. 2010.

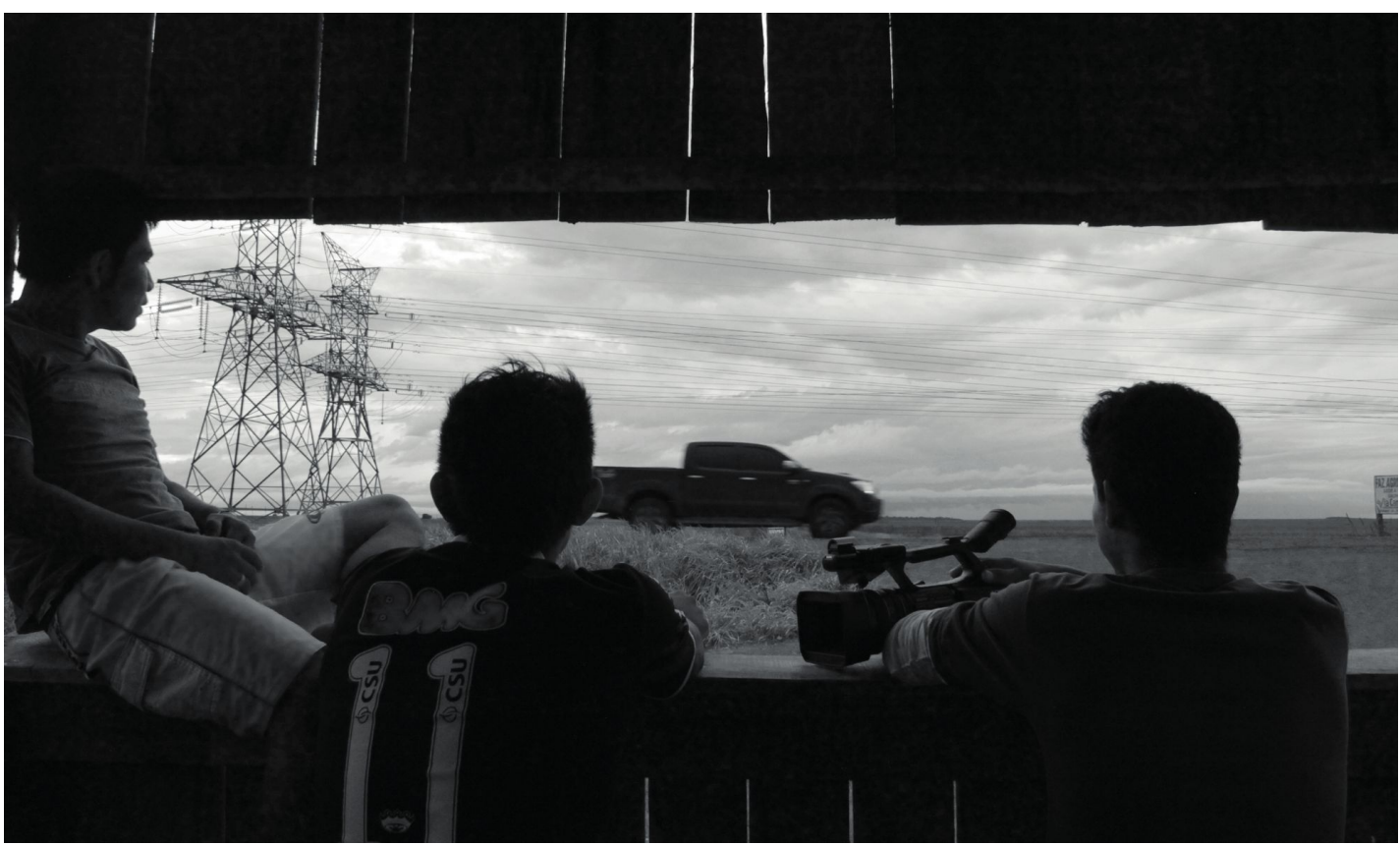

2. Duas temporalidades: na banca para vender pequi, Ronilso, Atailson e Anderson participam de uma oficina de vídeo enquanto observam a "BR" e o"linhão". Autor: André Lopes. 2013.

cadernos de campo, São Paulo, n. 22, p. 135-143, 2013 


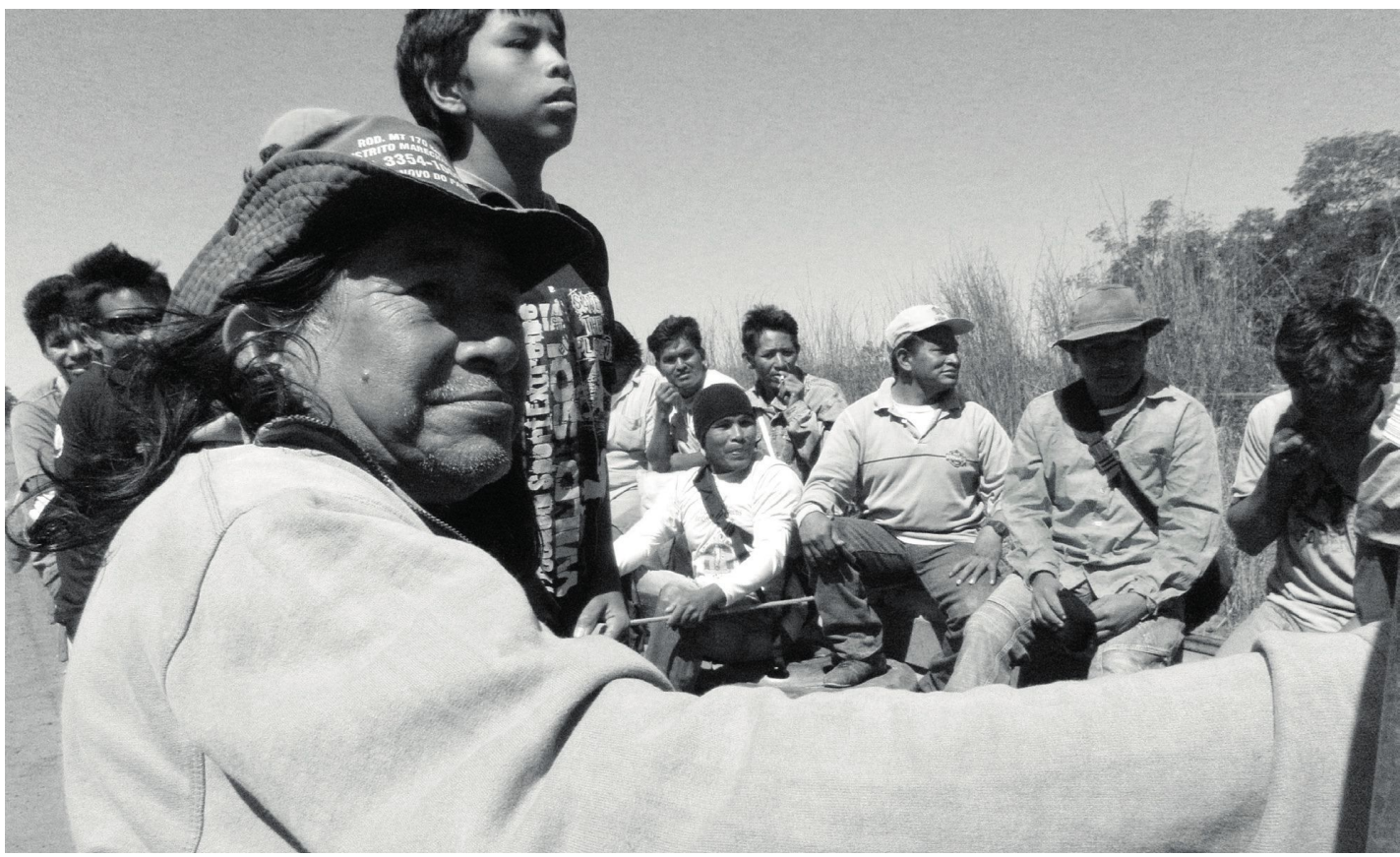

3. Pescaria, caça e política: em visita à pequena central hidrelétrica "Bocaiúva", 0 atual chefe Manoel Kanunxi (em primeiro plano) reivindica uma solução para a falta de peixes no rio Cravari. Na boleia do caminhão, a "gurizada", os "casados novos" e outros homens caçam durante o caminho e pescam na chegada. Autor: André Lopes. 2010.

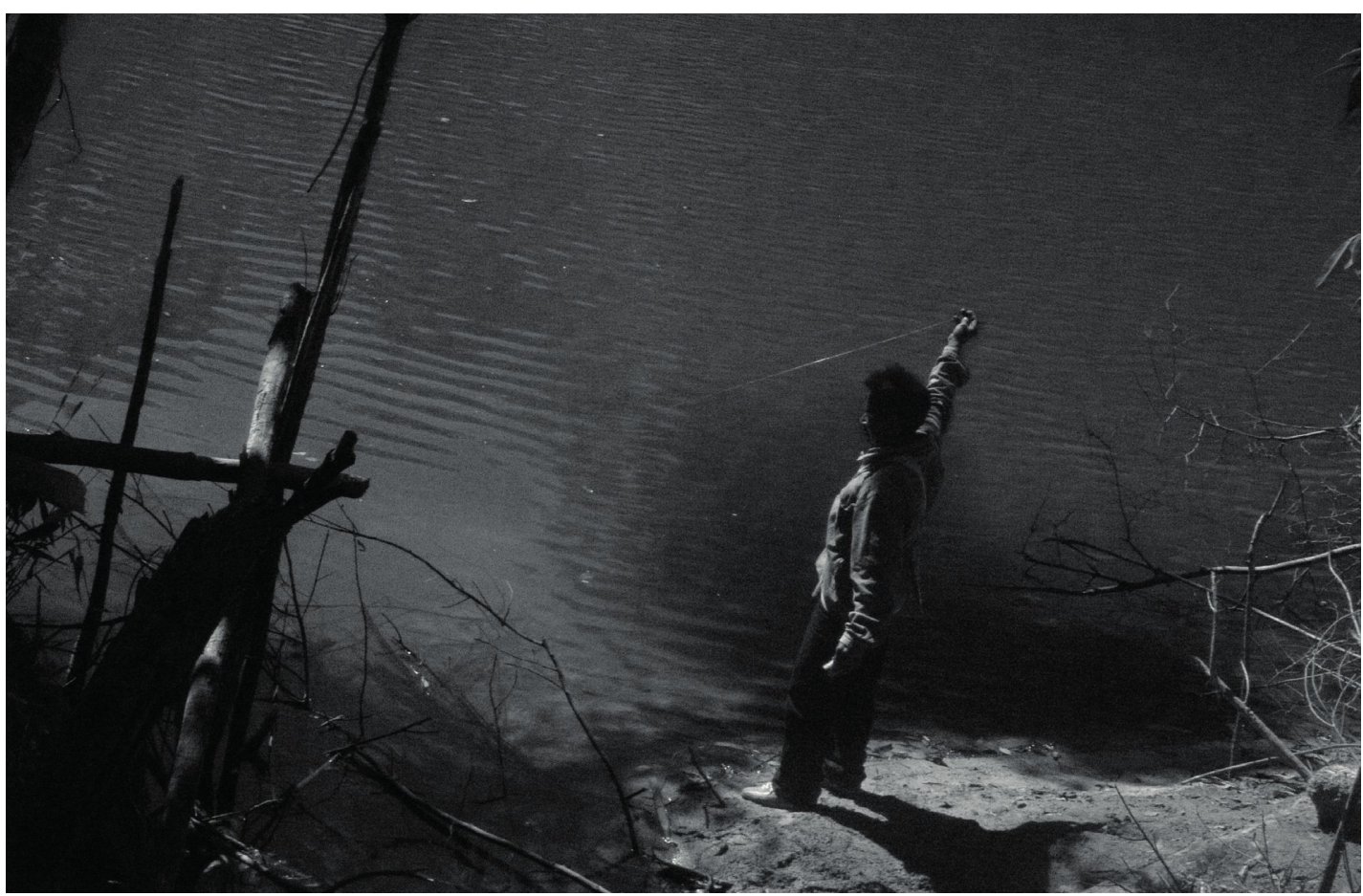

4. "Facada" esporadicamente se dedica à pescaria, mas nos últimos anos, devido à construção de uma barragem, ele tem se deslocado cerca de 80 quilômetros para encontrar peixes no rio Cravari. Autor: André Lopes. 2010. 
A ItinerênCIA da Vida Manoki| I4I

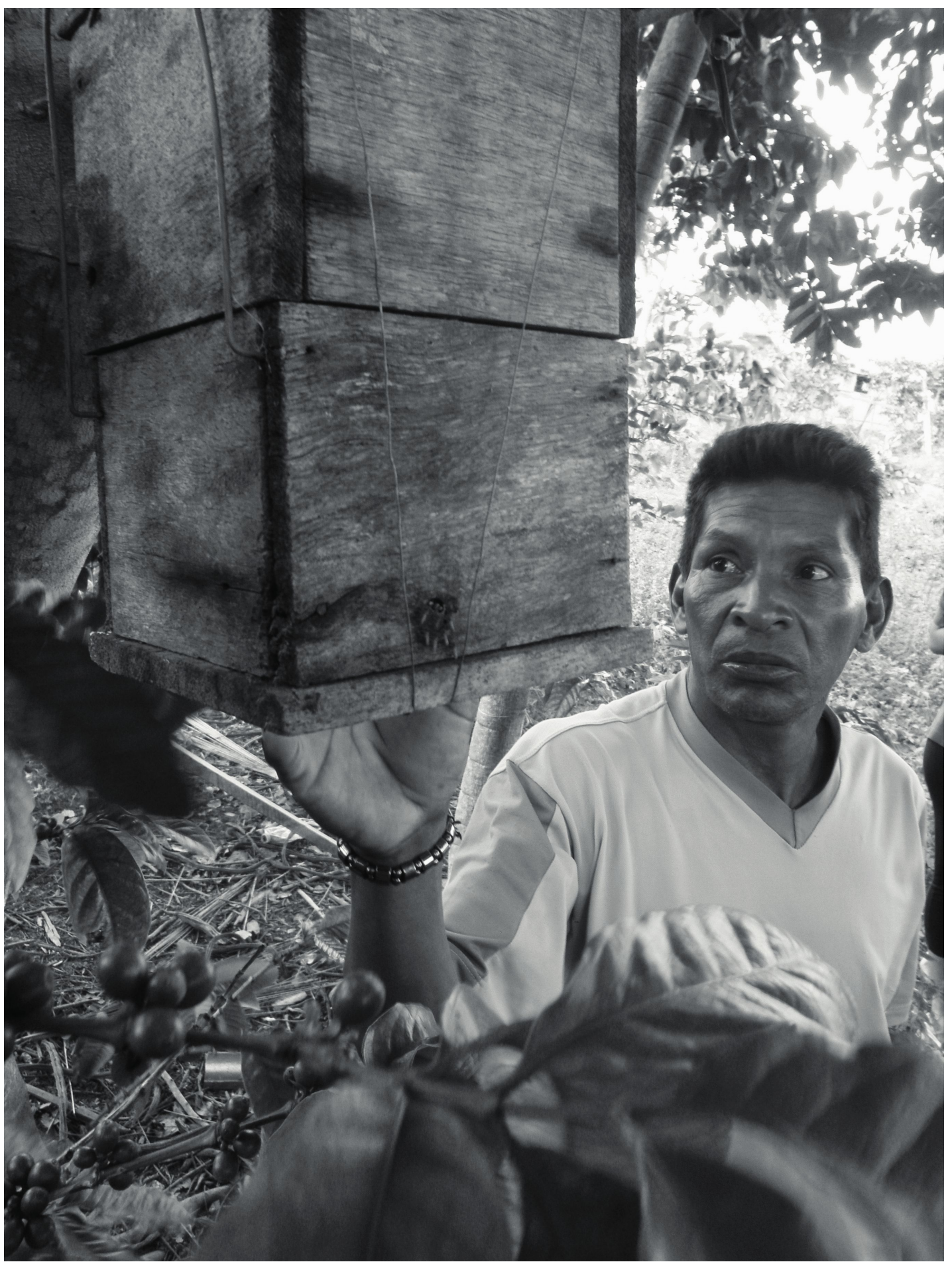

5. "Dito" examina caixa de abelhas jataí: depois de um período de boas vendas trabalhando com mel, 0 apicultor "enjoou" da atividade, embora pretenda dedicar-se novamente à ela em breve. Autor: André Lopes. 2009.

cadernos de campo, São Paulo, n. 22, p. 135-143, 2013 
I 42 ANDRÉ LOPES

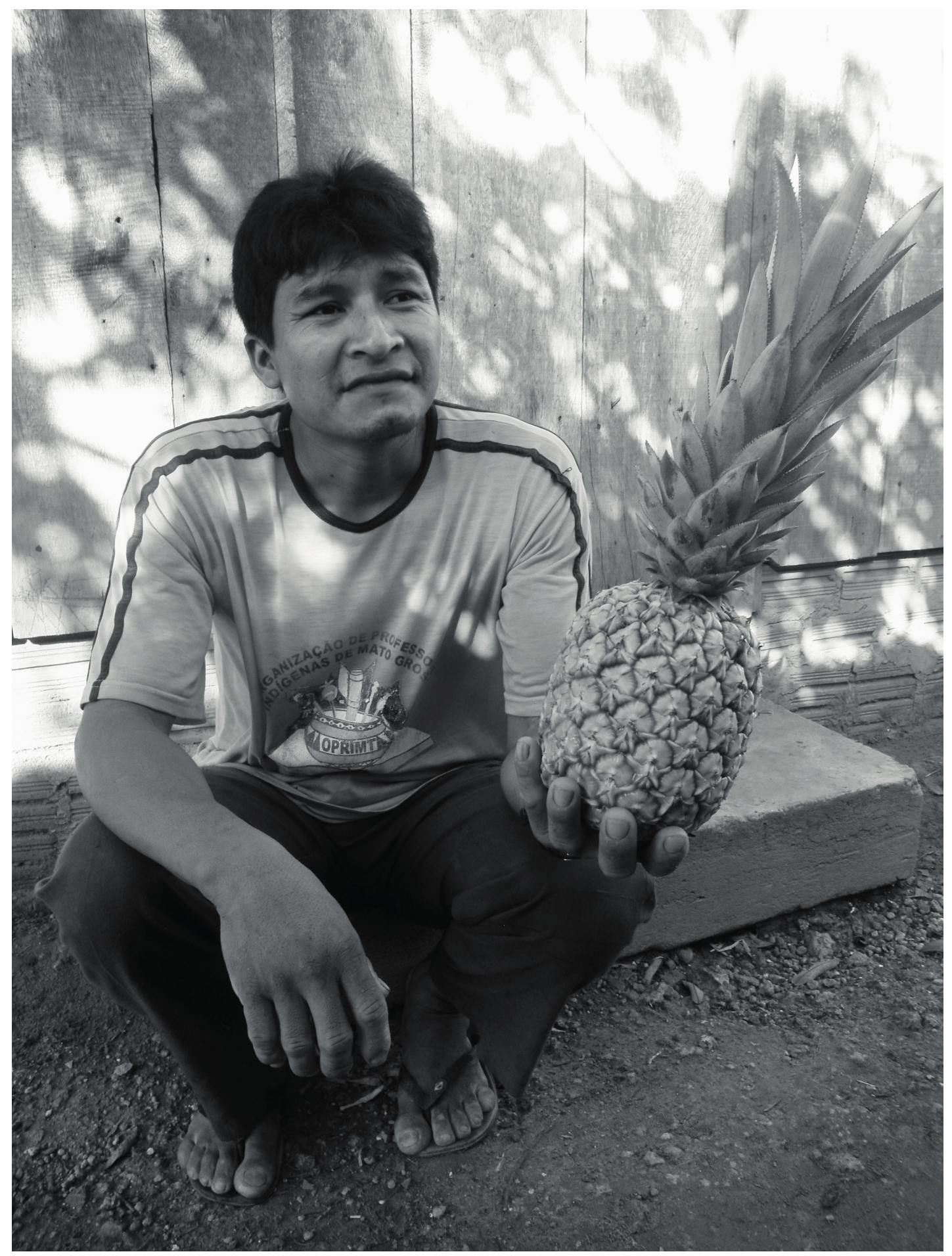

6. Marcelino Napiocu é um exemplo da "erudição produtiva" manoki: já foi presidente de associação, "cacique-geral", além de se dedicar periodicamente ao trabalho de pedreiro e de agricultor. Em 2010, produziu uma grande safra de abacaxis e vendeu boa parte na cidade, mas até agora não se dedicou mais à atividade. Autor: André Lopes. 2010. 
A ITINERÂNCIA DA VIDA ManoKI| I 43

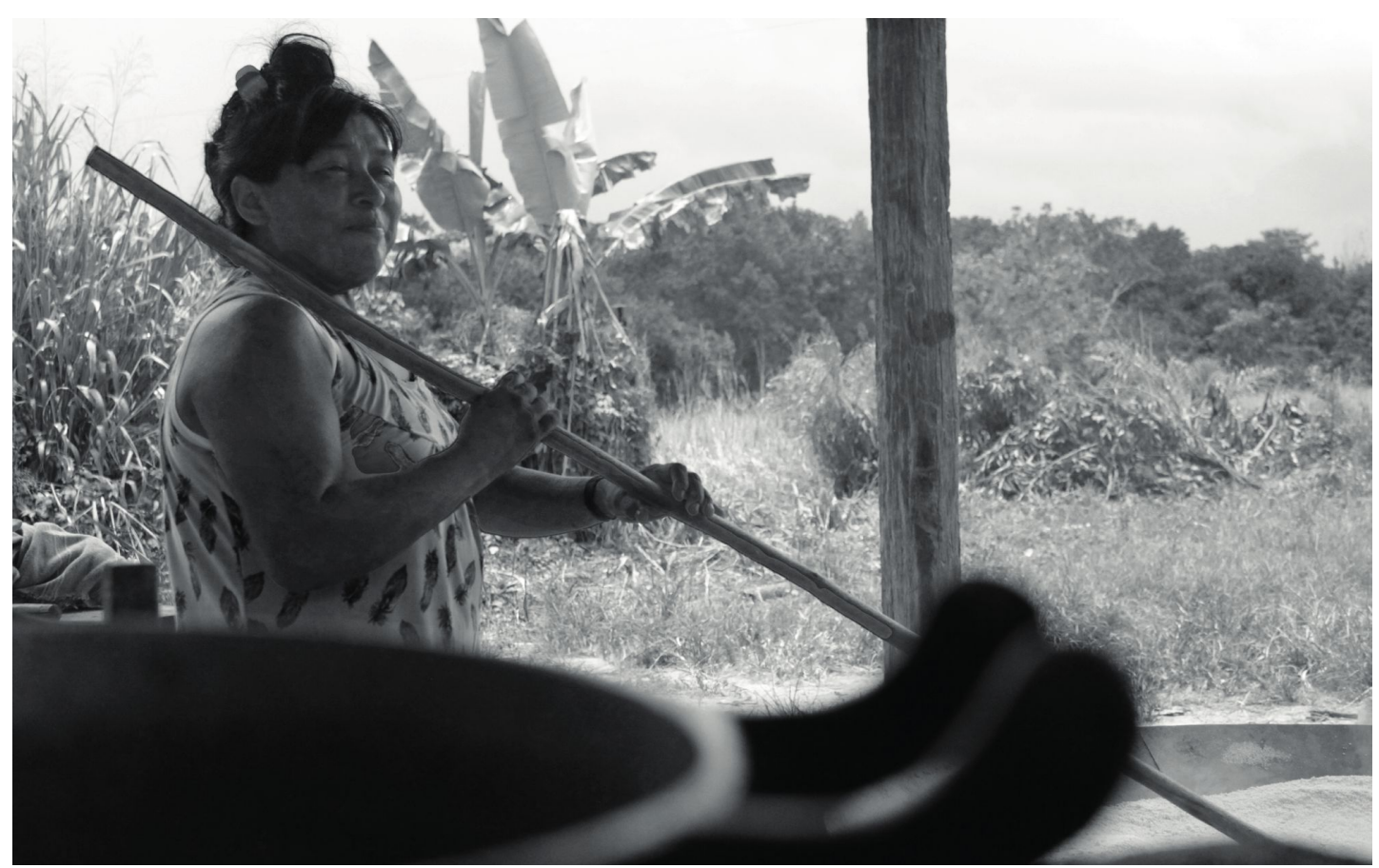

7. Terezinha se une a outras mulheres de sua família para produzirem farinha e venderem na própria terra indígena. Essa atividade está em voga neste ano: diversas aldeias pretendem seguir o exemplo do Cravari. Autor: André Lopes. 2013.

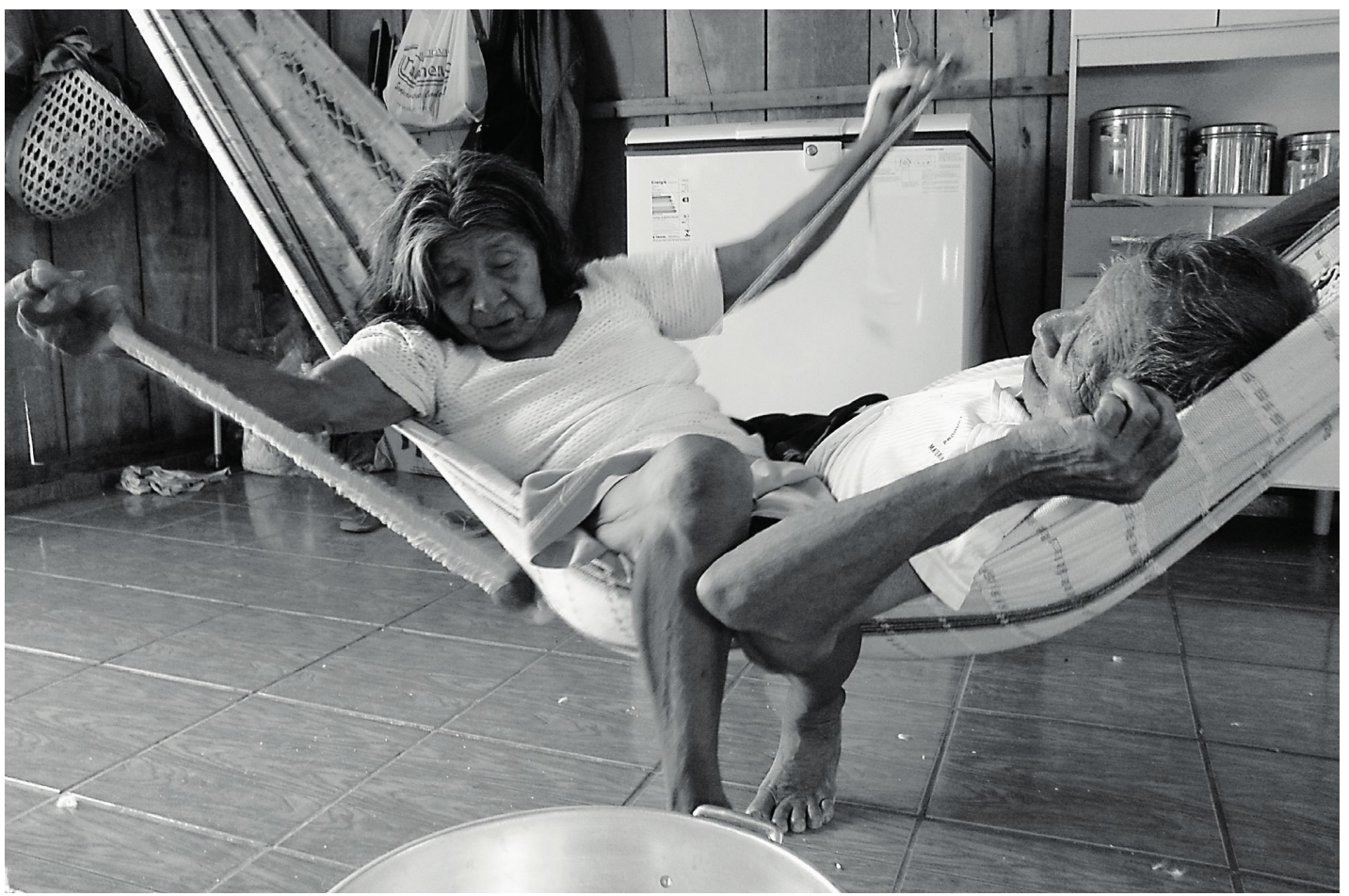

8. Enquanto fia 0 algodão, "velha” Angélica e seu esposo, "velho" Inácio, contam narrativas míticas e fofocas da aldeia. Autor: André Lopes. 2009.

cadernos de campo, São Paulo, n. 22, p. 135-143, 2013 